\title{
Tuberous sclerosis complex-associated renal angiomyolipomas: A single center study of 17 consecutive cases
}

\author{
HANG WANG* ${ }^{*}$, QILAI LONG* ${ }^{*}$ YIWEI WANG, LI LIU, LIN ZHOU and JIANMING GUO \\ Department of Urology, Zhongshan Hospital, Fudan University, Shanghai 200032, P.R. China
}

Received March 31, 2015; Accepted May 12, 2016

DOI: $10.3892 / \mathrm{ol} .2016 .4766$

\begin{abstract}
The aim of the present study was to investigate the treatment options for patients with tuberous sclerosis complex (TSC)-associated renal angiomyolipomas (AMLs). A total of 17 patients who were consecutively diagnosed with TSC-associated renal AMLs at the Department of Urology of Zhongshan Hospital between 1998 and 2012 were included in the study. The patient cohort included 7 males and 10 females with a mean age of 37.6 years (range, 18-62 years). A total of 12 patients were diagnosed with renal AML with TSC during physical examination (PE), while 5 patients were admitted to the Emergency Department of Zhongshan Hospital due to spontaneous rupture of renal AMLs. All renal lesions were examined by ultrasonography and abdominal computed tomography prior to treatment. The primary outcome measure was the kidney reservation rate (patients that had not received nephrectomies) in the rupture group and PE group. Both abdominal ultrasonography and CT revealed AMLs in all patients and the mean tumor size was $10.0 \pm 4.0 \mathrm{~cm}$ (range, $3.0-17.5 \mathrm{~cm}$ ). Overall, 9 patients underwent surgery, which included unilateral nephrectomy in 4 patients and unilateral partial nephrectomy/tumor enucleation in 5 patients. The remaining 8 patients received medical treatment. All patients were followed-up for between 10 and 67 months. One patient succumbed as a result of multiple organ failure, which was caused by hypovolemic shock due to the spontaneous rupture
\end{abstract}

Correspondence to: Professor Hang Wang or Professor Jianming Guo, Department of Urology, Zhongshan Hospital, Fudan University, 180 Fenglin Road, Shanghai 200032, P.R. China

E-mail: wang.hang@zs-hospital.sh.cn

E-mail: guo.jianming@zs-hospital.sh.cn

${ }^{*}$ Contributed equally

Abbreviations: AMLs, angiomyolipomas; TSC, tuberous sclerosis complex; CT, computed tomography; NSS, nephron sparing surgeries; PN, partial nephrectomy; RCC, renal cell carcinoma; $\mathrm{MR}$, magnetic resonance; mTORi, mammalian target of rapamycin inhibitor

Key words: renal AMLs, TSC, PN, surgical therapy, mTORi of renal AML. The kidney reservation rate during surgery was $87.5 \%$ (7/8) in the PE group and 25\% (1/4) in the spontaneous rupture group. The management of TSC-associated renal AMLs differs from that of solitary sporadic AMLs. Surgical therapy is recommended following careful risk-benefit analysis.

\section{Introduction}

Tuberous sclerosis complex (TSC) is an autosomal dominant disorder transmitted by two genes: TSC1 and TSC2, which are located on chromosomes 9q34 and 16p13.3, respectively (1). TSC is a rare genetic disease, which was first described in depth by Bourneville in 1880, with an incidence of 1 case per 6,000 individuals worldwide $(2,3)$. TSC may affect any organ or system (4,5); however, neurological symptoms are the most common manifestations of the disease. In total, $20 \%$ of patients experience seizures and $\sim 50 \%$ of those patients experience cognitive impairment, autism or other behavioral disorders, such as anxiety and depression (6,7). Renal lesions, including angiomyolipomas (AMLs), renal cysts, renal cell carcinoma and oncocytomas, are the second most common presentation associated with TSC, which occur in $50-80 \%$ of patients (8-10).

TSC was originally identified as a neurological and dermatological disorder; however, renal disease is the leading cause of mortality in adults with TSC (11), as AMLs exhibit a high risk of hemorrhage and may invade adjacent normal renal parenchyma, which leads to chronic kidney disease and end stage renal disease (12). The etiologies of AMLs with and without TSC are different. Compared with sporadic angiomyolipomas, TSC-associated angiomyolipomas tend to arise in multiples and bilaterally, at a younger age and be predominant in females, grow more aggressively and be more symptomatic (13). Therefore, the treatment of AMLs in TSC patients is much more complex than that for sporadic AML. Treatment strategies include active surveillance, embolization, and nephron sparing surgeries (NSS), such as partial nephrectomy (PN) or ablative therapy. In the present study, the treatment of 17 patients with TSC-associated renal AMLs, who underwent treatment at the Department of Urology, Zhongshan Hospital (Shanghai, China), was retrospectively analyzed, to identify a feasible strategy for surgical management. 
A

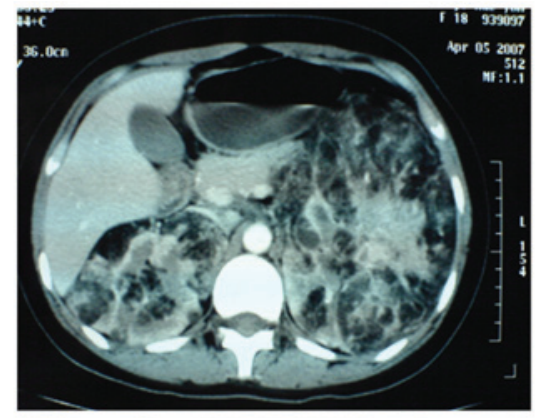

C

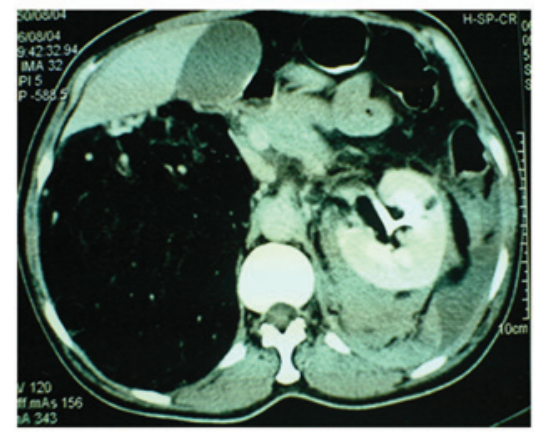

B

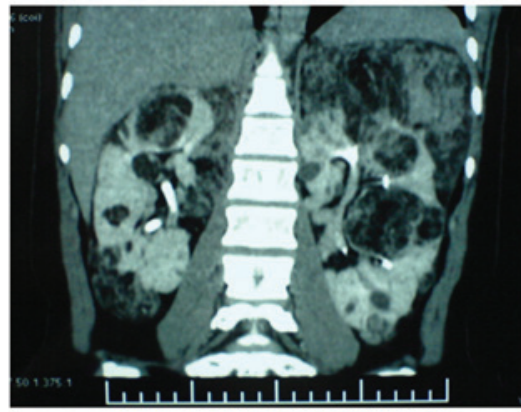

D

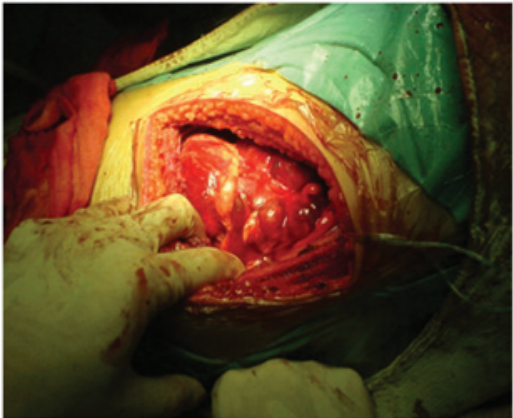

Figure 1. (A) Axial and (B) coronal CT scans revealed multiple AMLs in the kidneys. (C) CT scan revealing a right renal AML occupying a large section of the kidney. (D) AMLs identified during surgery. CT, computed tomography; AMLs, angiolipomas.

\section{Patients and methods}

Patients. A total of 17 patients diagnosed with TSC-associated renal AMLs in the bilateral kidney, that were admitted to the Department of Urology, Zhongshan Hospital (Shanghai, China) between January 1998 and December 2012 were retrospectively analyzed. Ethical approval was obtained from the Clinical Research Ethics Committee of Zhongshan Hospital of Fudan University. All patients provided written informed consent for the collection and use of their tissue samples and clinical data. The patient cohort included 7 males and 10 females with a mean age of 37.6 years (range, 18-62 years). Renal AMLs were identified during physical examination (PE) in 12 patients, while 5 cases were identified due to spontaneous hemorrhage. A total of 10 patients presented with tumor-associated symptoms, including a palpable mass in 8 patients and flank pain in 3 patients. TSC was confirmed in all cases following comprehensive examination, which was performed according to the 2012 diagnostic criteria of the International TSC Consensus Group (14).

All cases underwent ultrasound and contrast-enhanced computed tomography (CT) as the initial diagnostic modality. The AML was diagnosed when a highly echogenic lesion was identified on the ultrasound and when masses of dense fat were found on the kidneys using CT scans. MR was required in cases where diagnosis proved difficult. A total of 7 patients underwent brain CT examination. Additional symptoms, including multiple fibroids of skin, facial angiofibromas, subependymal nodules and shagreen patches were examined. Epilepsy status of the patients and family history were also considered. AML size was defined as the maximum diameter of the largest tumor identified on CT scan.

Treatments. A total of 12 surgeries were performed on 9 patients. Of these, 4 nephrectomies and $8 \mathrm{PN} /$ tumor enucleations were performed. None of the tumors were considered to be malignant. Nephrectomy and PN were performed as described previously (15). Simple enucleation of renal AML was performed for cases with large AML or AML with hematoma. The tumors were enucleated along the capsule.

Statistical analysis. IBM SPSS version 19.0 (IBM SPSS, Armonk, NY, USA) was used for the statistical analysis. Comparisons of categorical data were analyzed using Fisher's exact test. P-values were two-tailed, and differences were considered significant at values of $\mathrm{P}<0.05$.

\section{Results}

Ultrasonography revealed highly echogenic lesions in both kidneys in all patients and mixed echogenic masses in patients with spontaneous ruptures of the kidney. Abdominal CT scans revealed masses of dense fat within the tumor in 16 patients (Fig. 1). One patient exhibited no significant intratumoral fat density on the CT and was subsequently diagnosed using MR. The mean tumor size was $10.0 \pm 4.0 \mathrm{~cm}$ (range, $3.0-17.5 \mathrm{~cm}$ ) In addition to renal AMLs, multiple fibroids and facial angiofibromas were also identified in all 17 patients, periungual fibroma in 9 patients, shagreen patches in 3 patients and subependymal nodules with calcification in 5 patients, which were identified by brain CT (Fig. 2). A total of 5 patients had epilepsy and 8 patients reported a family history of epilepsy.

Unilateral nephrectomy was performed in 4 patients, of which 3 cases required emergency treatment due to life-threatening hemorrhage following spontaneous rupture of AMLs, while one case underwent the procedure due to large lesions $(>15 \mathrm{~cm})$. Of these 4 cases, 2 patients underwent prophylactic contralateral PN/tumor enucleation 3 and 6 months following initial surgery for spontaneous rupture of AML. One patient underwent unilateral tumor enucleation in the right side of the kidney with 
Table I. Spontaneous rupture group patient demographics and outcomes.

\begin{tabular}{|c|c|c|c|c|c|c|}
\hline \multirow[b]{2}{*}{ Gender } & \multirow{2}{*}{$\begin{array}{l}\text { Age, } \\
\text { years }\end{array}$} & \multirow{2}{*}{$\begin{array}{l}\text { AML size, } \\
\mathrm{cm}\end{array}$} & \multirow[b]{2}{*}{ Features of TSC } & \multicolumn{2}{|c|}{ Treatment } & \multirow[b]{2}{*}{ Outcome } \\
\hline & & & & Right Kidney & Left Kidney & \\
\hline $\mathrm{F}$ & 21 & 12.0 & $\begin{array}{l}\text { Facial angiofibromas, } \\
\text { renal AML }\end{array}$ & Nephrectomy ${ }^{\mathrm{a}}$ & $\begin{array}{l}\text { Partial } \\
\text { nephrectomy }^{\mathrm{b}}\end{array}$ & Alive \\
\hline M & 32 & 12.0 & $\begin{array}{l}\text { Facial angiofibromas, periungual } \\
\text { fibroma, renal AML }\end{array}$ & Nephrectomy $^{\mathrm{c}}$ & Follow-up & Dead \\
\hline $\mathrm{F}$ & 56 & 17.5 & $\begin{array}{l}\text { Facial angiofibromas, } \\
\text { renal AML }\end{array}$ & $\begin{array}{l}\text { Tumor } \\
\text { enucleation }^{\mathrm{a}}\end{array}$ & $\begin{array}{l}\text { Tumor } \\
\text { enucleation }^{\mathrm{b}}\end{array}$ & Alive \\
\hline M & 55 & 14.0 & $\begin{array}{l}\text { Periungual fibroma, subependymal } \\
\text { nodule, renal AML }\end{array}$ & Nephrectomy ${ }^{\mathrm{a}}$ & Follow-up & Alive \\
\hline $\mathrm{F}$ & 52 & 12.0 & $\begin{array}{l}\text { Facial angiofibromas, shagreen } \\
\text { patch, periungual fibroma, } \\
\text { renal AML }\end{array}$ & Follow-up & Nephrectomy ${ }^{\mathrm{a}}$ & Alive \\
\hline
\end{tabular}

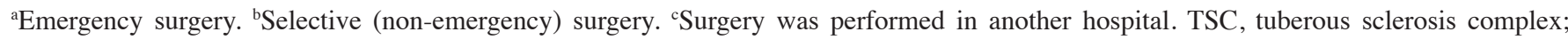
AML, angiolipoma; M, male; F, female.
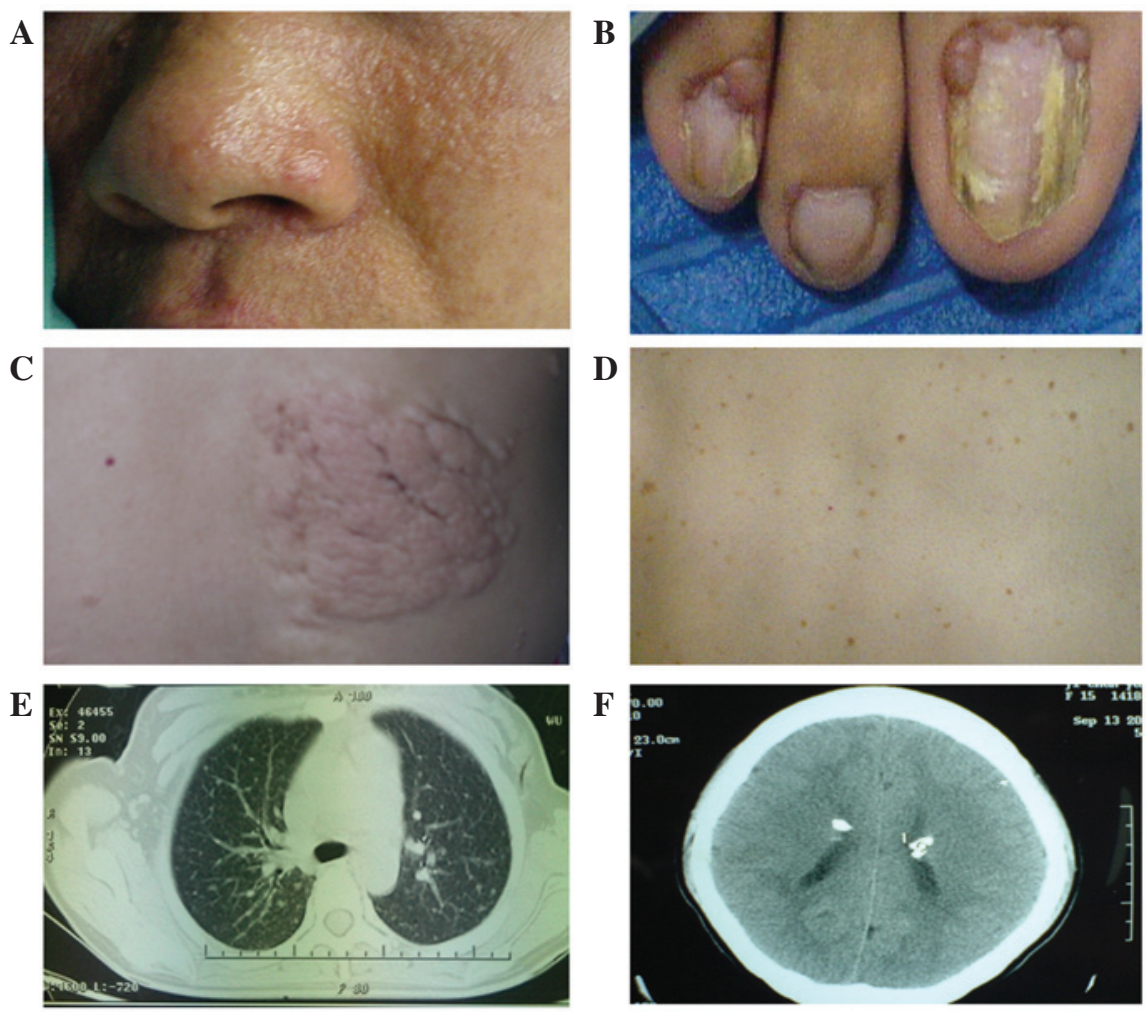

Figure 2. Additional symptoms of TSC, including (A) facial angiofibromas, (B) periungual fiberomata, (C) shagreen patches, (D) confetti skin lesions, (E) periungual fiberomata of the lung.and (F) subependymal nodules with calcification in the brain were identified in all patients.

contralateral tumor enucleation 4 months after initial surgery due to a large tumor $(8 \mathrm{~cm})$ in the right side and hematoma following spontaneous rupture of an AML lesion, $17.5 \mathrm{~cm}$ in size, in the left side of the kidney. Unilateral PN/tumor enucleation was performed in 4 patients that exhibited large lesions $(\geq 5 \mathrm{~cm})$ as a precaution. The other 8 patients received symptomatic medical treatment, for example controlling blood pressure for hypertension and pain relief for abdominal pain. The mean follow-up time for the patients was $44 \pm 17$ months (range, 10-67 months) during which 1 patient succumbed due to multiple organ dysfunction caused by hypovolemic shock that had resulted from spontaneous rupture of left renal AML. Notably, this patient had undergone right side nephrectomy at the First People's Hospital of Jiashan, Jiaxing, China, 6 years previously, due to the spontaneous rupture of AML. The patient was transfered to our hospital due to spontaneous rupture of the AML on June 2010. Patient demographics and outcomes are shown in Tables I and II. 
Table II. Physical examination group patient demographics and outcomes.

\begin{tabular}{|c|c|c|c|c|c|c|}
\hline \multirow[b]{2}{*}{ Gender } & \multirow{2}{*}{$\begin{array}{l}\text { Age, } \\
\text { years }\end{array}$} & \multirow{2}{*}{$\begin{array}{l}\text { AML size, } \\
\mathrm{cm}\end{array}$} & \multirow[b]{2}{*}{ Features of TSC } & \multicolumn{2}{|c|}{ Treatment } & \multirow[b]{2}{*}{ Outcome } \\
\hline & & & & Right Kidney & Left Kidney & \\
\hline $\mathrm{F}$ & 26 & 5.0 & Periungual fibroma, renal AML & Follow-up & $\begin{array}{l}\text { Partial } \\
\text { neprectomy }^{\mathrm{a}}\end{array}$ & Alive \\
\hline M & 25 & 13.0 & $\begin{array}{l}\text { Facial angiofibromas, periungual } \\
\text { fibroma, subependymal nodule, } \\
\text { renal AML }\end{array}$ & Follow-up & Follow-up & Alive \\
\hline $\mathrm{F}$ & 37 & 9.0 & Facial angiofibromas, renal AML & Follow-up & Follow-up & Alive \\
\hline M & 49 & 10.0 & Facial angiofibromas, renal AML & Follow-up & Follow-up & Alive \\
\hline $\mathrm{F}$ & 18 & 15.0 & $\begin{array}{l}\text { Facial angiofibromas, } \\
\text { subependymal nodule, renal AML }\end{array}$ & $\begin{array}{l}\text { Tumor enucleation } \\
6 \text { months later }{ }^{\mathrm{a}, \mathrm{b}}\end{array}$ & Nephrectomy ${ }^{\mathrm{a}}$ & Alive \\
\hline M & 19 & 5.5 & Facial angiofibromas, renal AML & Follow-up & Follow-up & Alive \\
\hline $\mathrm{F}$ & 62 & 3.0 & $\begin{array}{l}\text { Confetti skin lesion, hepatic } \\
\text { hamartoma, renal AML }\end{array}$ & Follow-up & $\begin{array}{l}\text { Partial } \\
\text { neprectomy }^{\mathrm{a}}\end{array}$ & Alive \\
\hline M & 32 & 7.0 & $\begin{array}{l}\text { Facial angiofibromas, shagreen } \\
\text { patch, periungual fibroma, renal AML }\end{array}$ & Follow-up & $\begin{array}{l}\text { Partial } \\
\text { neprectomy }^{\mathrm{a}}\end{array}$ & Alive \\
\hline $\mathrm{F}$ & 29 & 9.0 & Facial angiofibromas, renal AML & Follow-up & $\begin{array}{l}\text { Tumor } \\
\text { enucleation }^{\mathrm{a}}\end{array}$ & Alive \\
\hline $\mathrm{F}$ & 51 & 10.0 & $\begin{array}{l}\text { Facial angiofibromas, subependymal } \\
\text { nodule, periungual fibroma, renal AML }\end{array}$ & Follow-up & Follow-up & Alive \\
\hline $\mathrm{F}$ & 22 & 9.0 & $\begin{array}{l}\text { Facial angiofibromas, shagreen patch, } \\
\text { lung periungual fibroma, renal AML }\end{array}$ & Follow-up & Follow-up & Alive \\
\hline M & 18 & 8.0 & $\begin{array}{l}\text { Facial angiofibromas, subependymal } \\
\text { nodule, periungual fibroma, renal AML }\end{array}$ & Follow-up & Follow-up & Alive \\
\hline
\end{tabular}

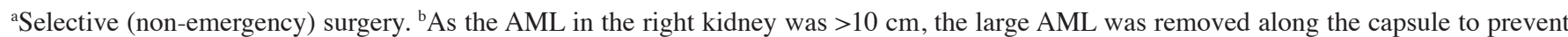
spontaneous rupture. TSC, tuberous sclerosis complex; AML, angiolipoma; M, male; F, female.

Table III. Surgery demographics of the spontaneous rupture and PE groups.

\begin{tabular}{lccc}
\hline Surgery & $\begin{array}{c}\text { Rupture } \\
\text { group, }\end{array}$ & $\begin{array}{c}\text { PE } \\
\text { group, } n\end{array}$ & P-value \\
\hline Nephrectomy & 3 & 1 & 0.067 \\
Partial nephrectomy & 1 & 7 & \\
\hline
\end{tabular}

P-value calculated using Fisher's exact test. PE, physical examination.

The kidney reservation rate during surgery was $87.5 \%$ (7/8) in the PE group and 25\% (1/4) in the spontaneous rupture group. A study with additional cases is required to verify the differences between the rupture group and PE group, since the P-value was 0.067 using Fisher's exact test, which is close to 0.05 . The surgery demographics of each group are listed in Table III. AMLs with or without hemorrhage were confirmed by pathological examination in 9 cases following surgery.

\section{Discussion}

TSC is a rare disease, which may affect any organ or system, and patients most commonly present with skin and neurological symptoms (4-6). Renal manifestations are the second most common symptom associated with TSC, occurring in $50-80 \%$ of patients with TSC $(6,10,16)$. The renal lesions that commonly occur in TSC patients include AMLs, renal cysts and renal cell carcinoma (RCC) (8-10). The incidence of RCC in TSC patients is extremely low, which is similar to that in healthy individuals, and can be easily diagnosed by CT or MR scan. Renal cysts occur in $20 \%$ of patients with TSC and tend to stabilize with increasing age (16). AML is the most common renal manifestation and $66.6 \%$ of TSC patients develop multiple renal AML (17-19). Treatment for diseases of the nervous system has markedly improved; however, long-term survival depends on the effective control of kidney disease in TSC patients. Spontaneous rupture of renal AML is the primary cause of mortality in adult TSC patients (11). In the present study, 29.4\% (5/17) of patients were admitted to hospital due to spontaneous rupture of the affected kidney, of which $20 \%(1 / 5)$ of patients succumbed due to blood loss. Therefore, the management of renal AMLs is extremely important in treating TSC patients.

At present, the management of renal AMLs in TSC patients is the same as that for sporadic AMLs. Surgery is considered essential if the tumor diameter is $>4 \mathrm{~cm}$, as $50 \%$ of tumors spontaneously rupture, leading to life-threatening shock in $33.3 \%$ of patients. However, AMLs in TSC patients exhibit different features when compared with sporadic AMLs. Firstly, 
AMLs in TSC patients are always bilateral and multiple and thus, surgery is not curative. Secondly, the tumor volume of TSC-associated AMLs are often larger than sporadic AMLs and thus, avoiding nephrectomy is difficult, particularly when spontaneous ruptures occur. In the present study, only $25 \%$ (1/4) of kidneys were preserved successfully during surgery for spontaneous ruptured AMLs and one patient succumbed due to blood loss. However, the kidney reservation rate was $87.5 \%$ (7/8) in the PE group. Thirdly, both sides of TSC-associated AMLs exhibit a risk of spontaneous rupture and hemorrhage, even following nephrectomy, and the remaining lesions in the contralateral kidney may continue to grow, leading to life-threatening complications. Furthermore, removal of one kidney may significantly increase the probability of renal failure if spontaneous rupture occurs in the contralateral kidney. At present, standard guidelines for the management of TSC-associated AMLs remain to be established.

We hypothesize that the management of renal AMLs in TSC patients should be different from patients with sporadic AMLs, particularly with regard to surgical treatment. As TSC-associated AMLs usually arise in multiples and bilaterally, growth faster and are more likely to spontaneously hemorrhage compared with sporadic AMLs, surgical therapies should be performed actively following a cautious risk-benefit analysis. The risk of hemorrhage must be evaluated and a comprehensive treatment plan should be established according to tumor location and size, which aims to preserve the kidney. It is impossible to cure multiple AMLs without nephrectomy and thus, treatment should focus on kidney reservation and prevention of life-threatening hemorrhage. The tumor size must be monitored closely during follow-up, as it may increase rapidly. Surgery is the first line treatment and PN/tumor enucleation should be performed immediately, even if the tumor size is $<4 \mathrm{~cm}$. Tumor enucleation is useful in surgical treatment, as it involves the removal of the large tumor in addition to the capsule or sub capsule. In the present study, 3 patients received 4 tumor enucleations, including 1 patient with a tumor size of $>10 \mathrm{~cm}$. Although the control rate (rate of the prevention of spontaneous AML rupture) is lower in TSC-associated AMLs compared with sporadic AMLs (40 vs. 100\%), endovascular embolization may be a feasible alternative in TSC patients with bilateral large renal AMLs, solitary kidney with huge AML or AML associated with a higher risk of severe hemorrhage during surgery (20). Additionally, ablative therapies, including radiofrequency ablation (RFA) or cryoablation, present alternatives to NSS and embolization for renal AML. RFA may be used safely and effectively for the treatment of small $(<4 \mathrm{~cm})$ and symptomatic renal AMLs, as shown previously (21). Conservative treatment and follow-up must not be performed blindly, as it may lead to kidney loss and life-threatening hemorrhage following the spontaneous rupture of AMLs. In the present study, 1 patient succumbed due to spontaneous rupture of AML in the left kidney. Notably, this patient had received nephrectomy due to spontaneous rupture of AML in the right kidney 6 years previously. Furthermore, the maximum size of the endogenous tumor in the left kidney had been $>10 \mathrm{~cm}$ prior to rupture; however, surgery was postponed due to the hesitation of the patient and to allow the doctor to make the right decision.

In addition, a number of novel medical therapies for renal AMLs in TSC have been identified (12,22-24). After the identification of TSC1 and TSC 2 and their encoded proteins (hamartin and tuberin, respectively), the mammalian target of rapamycin (mTOR) complex1 was established as a downstream target of the hamartin/tuberin complex. Therefore, the use of mTOR inhibitors (mTORis) may present a potential targeted therapy as they have been demonstrated to affect the AML volume (12,22-24). A multicentre randomized double-blind placebo-controlled trial by Bissler et al (25) demonstrated that everolimus, an mTORi, was more effective than a placebo in AML response rate (42 vs. $0 \%$ ), skin lesion response rate (26 vs. 0\%), and the median time to AML progression was 11.4 months for the placebo and was not reached for everolimus. Furthermore, at week $24,>50 \%$ everolimus patients exhibited a $\geq 50 \%$ reduction from baseline in target AML volume. Two other trials demonstrated that sirolimus, an associated mTORi, exhibited similar effects on AML volume $(24,26)$. Therefore, mTORis present a novel treatment for TSC patients that allows more nephrons to be spared, avoiding further AML growth.

In conclusion, AMLs occur with high frequency in patients with TSC and may lead to considerable hemorrhage, renal failure and mortality. The management of TSC-associated renal AMLs is different from that of solitary sporadic AMLs. Treatment must not only focus on treating the tumors, but should fully evaluate the risk of hemorrhage and actively avoid nephrectomy. Surgical therapies should be performed actively following comprehensive risk-benefit analysis, and should be considered for fast-growing tumors even if the maximum tumor size is $<4 \mathrm{~cm}$. Furthermore, mTOR is present a potential pharmacological treatment modality for TSC-associated renal AMLs. The results of the present study indicate that active surgical treatment is useful to prevent spontaneous hemorrhage.

\section{References}

1. Winterkorn EB, Daouk GH, Anupindi S and Thiele EA: Tuberous sclerosis complex and renal angiomyolipoma: Case report and review of the literature. Pediatr Nephrol 21: 1189-1193, 2006.

2. Crino PB, Nathanson KL and Henske EP: The tuberous sclerosis complex. N Engl J Med 355: 1345-1356, 2006.

3. Bourneville DM: Tuberous sclerosis of the cerebral cortex: Intellectual disability and hemiplegic epilepsy. Arch Neurol (Paris) 1: 81-91, 1880 (In French).

4. Borkowska J, Schwartz RA, Kotulska K and Jozwiak S: Tuberous sclerosis complex: Tumors and tumorigenesis. Int J Dermatol 50: 13-20, 2011.

5. Yates JR: Tuberous sclerosis. Eur J Hum Genet 14: 1065-1073, 2006.

6. Franz DN, Bissler JJ and McCormack FX: Tuberous sclerosis complex: Neurological, renal and pulmonary manifestations. Neuropediatrics 41: 199-208, 2010.

7. de Vries PJ, Whittemore VH, Leclezio L, Byars AW, Dunn D, Ess KC, Hook D, King BH, Sahin M and Jansen A: Tuberous sclerosis associated neuropsychiatric disorders (TAND) and the TAND Checklist. Pediatr Neurol 52: 25-35, 2015.

8. Rakowski SK, Winterkorn EB, Paul E, Steele DJ, Halpern EF and Thiele EA: Renal manifestations of tuberous sclerosis complex: Incidence, prognosis, and predictive factors. Kidney Int 70: 1777-1782, 2006.

9. Henske EP: Tuberous sclerosis and the kidney: From mesenchyme to epithelium and beyond. Pediatr Nephrol 20: 854-857, 2005.

10. O'Callaghan FJ, Noakes MJ, Martyn CN and Osborne JP: An epidemiological study of renal pathology in tuberous sclerosis complex. BJU Int 94: 853-857, 2004.

11. Shepherd CW, Gomez MR, Lie JT and Crowson CS: Causes of death in patients with tuberous sclerosis. Mayo Clin Proc 66: 792-796, 1991

12. Dixon BP, Hulbert JC and Bissler JJ: Tuberous sclerosis complex renal disease. Nephron Exp Nephrol 118: e15-e20, 2011. 
13. Rabenou RA and Charles HW: Differentiation of sporadic versus tuberous sclerosis complex-associated angiomyolipoma. AJR Am J Roentgenol 205: 292-301, 2015.

14. Northrup $\mathrm{H}$ and Krueger DA; International Tuberous Sclerosis Complex Consensus Group: Tuberous sclerosis complex diagnostic criteria update: Recommendations of the 2012 Iinternational tuberous sclerosis complex consensus conference. Pediatr Neurol 49: 243-254, 2013.

15. Wang H,Zhou L, Guo J, Sun L, Long Q, Ma Y,Zhang L,Lin Z,Zhu T and Wang G: Mini-flank supra-12th rib incision for open partial nephrectomy compared with laparoscopic partial nephrectomy and traditional open partial nephrectomy. PloS One 9: e89155, 2014.

16. Ewalt DH, Sheffield E, Sparagana SP, Delgado MR and Roach ES: Renal lesion growth in children with tuberous sclerosis complex. J Urol 160: 141-145, 1998.

17. Steiner MS, Goldman SM, Fishman EK and Marshall FF: The natural history of renal angiomyolipoma. J Urol 150: 1782-1786, 1993.

18. Malone MJ, Johnson PR, Jumper BM, Howard PJ, Hopkins TB and Libertino JA: Renal angiomyolipoma: 6 case reports and literature review. J Urol 135: 349-353, 1986.

19. Curatolo P, Bombardieri R and Jozwiak S: Tuberous sclerosis. Lancet 372: 657-668, 2008.

20. Kothary N, Soulen MC, Clark TW, Wein AJ, Shlansky-Goldberg RD, Crino PB and Stavropoulos SW: Renal angiomyolipoma: Long-term results after arterial embolization. J Vasc Interv Radiol 16: 45-50, 2005.

21. Castle SM, Gorbatiy V, Ekwenna O, Young E and Leveillee RJ: Radiofrequency ablation (RFA) therapy for renal angiomyolipoma (AML): An alternative to angio-embolization and nephron-sparing surgery. BJU Int 109: 384-387, 2012.
22. Curatolo $P$ and Moavero R: $m$ TOR inhibitors in tuberous sclerosis complex. Curr Neuropharmacol 10: 404-415, 2012.

23. Budde $\mathrm{K}$ and Gaedeke J: Tuberous sclerosis complex-associated angiomyolipomas: Focus on mTOR inhibition. Am J Kidney Dis 59: 276-283, 2012.

24. Bissler JJ, McCormack FX, Young LR, Elwing JM, Chuck G, Leonard JM, Schmithorst VJ, Laor T, Brody AS, Bean J, et al: Sirolimus for angiomyolipoma in tuberous sclerosis complex or lymphangioleiomyomatosis. N Engl J Med 358: 140-151, 2008.

25. Bissler JJ, Kingswood JC, Radzikowska E, Zonnenberg BA, Frost M, Belousova E, Sauter M, Nonomura N, Brakemeier S, de Vries PJ, et al: Everolimus for angiomyolipoma associated with tuberous sclerosis complex or sporadic lymphangioleiomyomatosis (EXIST-2): A multicentre, randomised, double-blind, placebo-controlled trial. Lancet 381: 817-824, 2013.

26. Davies DM, de Vries PJ, Johnson SR, McCartney DL, Cox JA, Serra AL, Watson PC, Howe CJ, Doyle T, Pointon K, et al: Sirolimus therapy for angiomyolipoma in tuberous sclerosis and sporadic lymphangioleiomyomatosis: A phase 2 trial. Clin Cancer Res 17: 4071-4081, 2011. 